\title{
GOMPARISON OF THE OPTICAL ISOMERS OF XYLOPININE
}

\author{
HIRONORI NAKANISHI, TADAO OKEGAWA AND KIRO SHIMAMOTO \\ Defartment of Pharmacology, Faculty of Medicine, Kyoto University, Sakyo-ku, Kyoto \\ Received for publication July 1965
}

The pharmacological effects of $l$-xylopinine, 2,3,10,1l-tetramethoxy-5,6-13,13a-tetrahydro-8-dibcnzo(a-g)quinolizine citrate in a varicty of experimental animals have been reported by Nakanishi $(1,2)$ and Yamamoto (3). The $l$-isomer produced a sedation with a concomitant manifestation of the resting waves in spontaneous EEG, depression on the reticular activating, specific and non-specific thalamocortical and hypothalamic activating systems and a gradually developing hypotension. All these effects derive presumedly from the peripheral and contral adrenolytic mechanisms. Despite of the similarity in chemical configuration with tctrabenazine, the compound was shown to producc no significant depletion of the tissue noradrenaline in rabbit (4). The current study deals with the comparison of the pharmacological effect of $l$-, $d l$-, and $d$-isomers of xylopinine hydrochloride.

\section{MEIHODS}

I) Behavioral and loxicity studies: Albino mice of dd-strain, weighing 14 to $17 \mathrm{~g}$ and of either sex, were used. The animals were kept in the animal room at the temperature of $22 \pm 2{ }^{\circ} \mathrm{C}$ and were allowed free access to the commercial diet (CLEA-GA-1) and drinking water. The behavioral and toxicity studies were performed in the similarly conditioned room. The graded doses of the isomers, dissolved in $0.3 \mathrm{ml}$ of physiological saline solution, were injected intraperitoneally to mice kept in an individual cage. A group of mice for one dose consisted of 8 . The behavioral changes of the mice in response to each dosc were observed at least for 12 hours after the administration and $\mathrm{LD}_{\mathrm{s}}$ was calculated from the number of the killed mice at 24 hours by the method of Litchficld and Wilcoxon.

The effects of the graded doses of the isomers, injected intraperitoncally, on the time course of the disappcarance of the righting reflex caused by the intraperitoneal injection of $70 \mathrm{mg} / \mathrm{kg}$ of hexobarbital sodium and $1.8 \mathrm{~g} / \mathrm{kg}$ of urethane and also by inhalation of cther were observed in mice. These anesthctics were given in such dose that the righting reflex disappeared for 25 to 40 minutes. For the inhalation of ether, the mice were placcd individually in a rectangular glass box, $10 \times 13 \times 15 \mathrm{~cm}$ in size and covered with a vinyl plate, and about $0.5 \mathrm{ml}$ of ether was instilled to abolish the righting reflex of the animal for about 40 minutes at the induction time of about 70 seconds. The number of mice used for one dose of the isomers was 10.

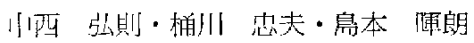


The intraperitoneal $\mathrm{LD}_{50}$ of $d l$-methamphetamine hydrochloride was previously. calculatcd at 24 hours after the administration. A group of 10 mice for one dose was kept in an individual cage. The various doses of these isomers were administered intraperitoneally immediately after, half and one hour after the administration of methamphetamine and the life-saving potencies of these isomers against the lethal effect of methamphetaminc were compared as difference in $\mathrm{LD}_{50}$.

2) Effects on the cardiovascular system: Effects of the isomers on the blood pressure were observed in the dogs anesthetized with intraperitoneal injection of $50 \mathrm{mg} / \mathrm{kg}$ of amobarbital sodium and also in the rabbits anesthetized with intraperitoneal injection of $1 \mathrm{~g} / \mathrm{kg}$ of urethanc. Further, effects of the isomers on the pressor responses to adrenaline and noradrenaline were compared in the dog.

3) Effects on the ccntractile response of vas deferens of guinea-pig to sympathetic stimuli: The vas deferens attached with hypogastric nerve was isolated following the technique of Huković (5), and the preparation was immersed in the oxygenated Krebs'solution at $37 \mathrm{C}$. The contraction of the preparation caused by stimulation of the hypogastric nerve with square wave pulse, submaximal in intensity, $20 / \mathrm{sec}$ in frequency and $1 \mathrm{msec}$ in duration, and by administration of $5 \times 10^{-6}$ of adrenaline was recorded on the smoked drum via an isotonic lever. The electrical stimulation was applied for 15 seconds at a time interval of 2 minutes. Effects of the various concentrations of the isomers on the adrenergic responses were comparatively observed. In addition, the modifying effects of the isomcrs on the responses of the isolated strips of uterus to adrenaline and noradrenalinc during estrous cycle in rats were also observed.

4) EEG stzdies: Rabbits, weighing 2.0 to $3.5 \mathrm{~kg}$, werc introduced a tracheal cannula under ether anesthcsia. The animal was fixed its head on the stereotaxic instrument of Todai Noken type. The cortical surface EEG was induced by means of a silver wire electrode placed on the dura mater covering the motor cortex. The round tip of the electrode was $1 \mathrm{~mm}$ in diameter. The EEGs in the deep brain structures were led monopolarly by means of an inserted steel electrode, $0.3 \mathrm{~mm}$ in diameter and insulated except its tip. The indifferent electrode was placed on the frontal cranium. The stimulating electrodes, made of steel and insulated cxcept their tips, were inserted into the brain stem reticular formation, and the Nucleus centre médian of the thalamus. The site of stimulation in the deep structures was determined according to the map devised by Sawyer et al. The distance between both tips of the stimulating electrodes was $1 \mathrm{~mm}$. The potential changes were recorded by the use of Sanci Sokki Electroenccphalograph, EA-101 type.

\section{RESULTS}

\section{Acute toxicily in mice}

\section{1. l-Xylopinine}

Significant changes of the behavior in mice were consistently observed by a single intraperitoneal injection of the doses above $30 \mathrm{mg} / \mathrm{kg}$. In response to $30 \mathrm{mg} / \mathrm{kg}$ the mouse 
showed the reduction in the spontaneous movement and the depression of the respiration accompanied with a slight activation of the avoidance responses to the external stimuli such as sound and mechanical stimulation of the pinna and conjunctiva. These effects lasted for about one hour. The increase of the dose to 40 or $50 \mathrm{mg} / \mathrm{kg}$ enhanced the depression of the spontaneous movement and respiration in latency, duration and degree. In additon, 20 to 30 minutes after the administration the tremor appeared first in the limbs expanded to the whole body. Thereafter, piloerection in the tail, squeaking response and impulsive running appeared successively. In serious cases, these effects led to the clonic or tetanic convulsion. All the mice which responded with the tetanic convulsion were killed by the respiratory arrest after several repetitions of the scizure. On the other hand, the mice which responded with the clonic seizure alone survived occassionally or showed a retarded death.

\section{2. dl-Xylopinine}

The intraperitoneal injection of $100 \mathrm{mg} / \mathrm{kg}$ of $d$-isomer depressed the spontaneous movements and respiration accompanied with moderate increase of the avoidance reflexes from 5 minutes after the administration. These effects lasted for one and half hours. The morc marked depression of movement and respiration caused by $130 \mathrm{mg} / \mathrm{kg}$ was followed with manifcstation of tremor in the whole body, piloerection in the tail and elevation of the tail. About half number of mice treated with this dose cxhibited the clonic convulsion and some of others the tetanic convulsion. In the acutely killed animals the respiratory arrest always preceded the cardiac one.

\section{3. d-Xylopinine}

From about 10 minutes after the intraperitoneal injection of $150 \mathrm{mg} / \mathrm{kg}$ of $d$-isomer the animals showed also the depression of the movement and respiration as well as the depression of the avoidance reflexes. Though the Haffner's pain reaction remained unaffected during the bchavioral depression caused by $l$-and $d l$-isomers, the $d$-isomer in the dose of $150 \mathrm{mg} / \mathrm{kg}$ depressed the same pain reaction. These depressing effects lasted for two hours or more, and the animals showed full recovery 12 hours after the administration. The depressing effect caused by $180 \mathrm{mg} / \mathrm{kg}$ lasted for two to three hours. Though further increase in the dose increased the number of the killed animals at 24 hours after the administration, tetanic or clonic convulsion was never observed.

The intraperitoneal $\mathbf{L D}_{50}$ of the isomers in mice is shown in Table 1 . The acute toxicity was highest in $l$-isomer and lowest in $d$-isomer. The intermediary toxicity of $d l$-isomer indicates the more depressing effect of $d$-isomer antagonizes the lethal effect of $l$-isomer.

TABLE 1. Acute toxicity $\left(\mathrm{LD}_{50}\right)$ of the isomers of xylopinine in a peritoneal route in mice.

\begin{tabular}{cccc}
\hline & $l$-Isomer & $d l$-Isomer & $d$-Isomer \\
\hline $\mathrm{LD}_{50}(\mathrm{mg} / \mathrm{kg})$ & 62 & 90 & 180 \\
& $(47.7-80.6)$ & $(60.0-135.0)$ & $(158.7 \cdot 306.0)$ \\
\hline
\end{tabular}


Il. Effects on the sleeping time of mice caused by hexobarbital, urethane and ether

1. Hexobarbital sodium

The duration of the ancsthesia by intraperitoneal injection of $70 \mathrm{mg} / \mathrm{kg}$ of hexobarbital sodium was not significantly affected by the combined administration of $5 \mathrm{mg} / \mathrm{kg}$ of either isomer. Howcver, the combined administration of either isomer in the doses of 10,20 and $30 \mathrm{mg} / \mathrm{kg}$ prolonged significantly the duration of the anesthesia caused by hexobarbital. When the anesthetic and the isomer were injected simultancously, the prolongation was most marked in $l$-isomer and least in $d$-isomer. On the other hand, the pronounced in $d$-isomer than in $l$-isomer in mice which received the same doses of xylopinine 15, 30 and 60 minutes before hexobarbital. The potentiation of hexobarbital anesthesia by the isomers subsided in parallel with the length of time elapsed after the previous treatment (Fig. 1). The motor excitement of the animals during the induction of hexobarbital effect was slightly depressed by $l$-isomer but not by $d$-isomer.

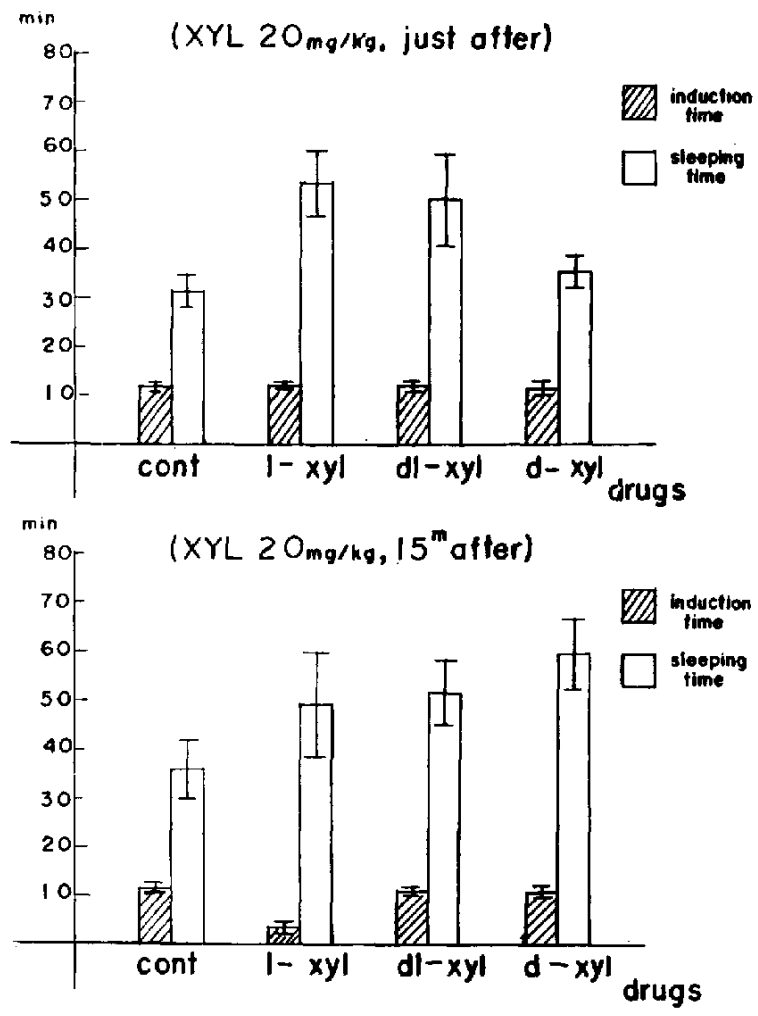

FIG. 1. The duration of the disappearance of the righting reflex and the length of the induction time by the intraperitoneal injection of $70 \mathrm{mg} / \mathrm{kg}$ of hexobarbital sodium in combination with $20 \mathrm{mg} / \mathrm{kg}$ of isomers just after and 15 minutes after.

\section{Urethane}

The intraperitoncal administration of the isomers 30 minutes before prolonged markedly the duration of the anesthesia by intraperitoncal injection of $1.8 \mathrm{~g} / \mathrm{kg}$ of 
urethane. The prolongation was more marked in $d$-isomer than in $l$-isomer. However, the prolongation by simultaneous administration of $20 \mathrm{mg} / \mathrm{kg}$. of either isomer with urethane was most marked in $l$-isomer and least in $d$-isomer. The prolongation of the urethane anesthesia by the dose of xylopinine was more marked than the samc effect on the hexobarbital anesthesia. The induction time was not affected by the dose of xylopinine (Fig. 2).

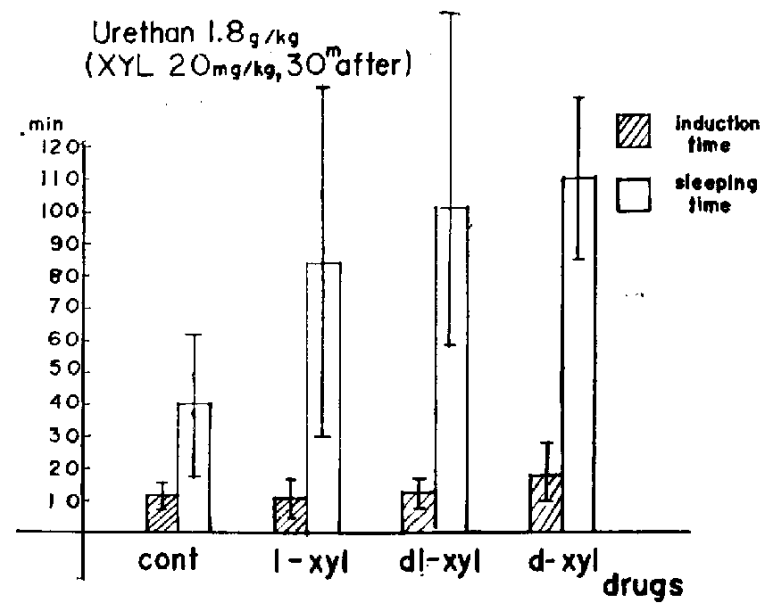

FIG. 2. The duration of the disappearance of the righting reflex and the length of the induction time by the intraperitoneal injection of $1.8 \mathrm{mg} / \mathrm{kg}$ of urethane in mice pretreated with the intrapcritoneal injection of $20 \mathrm{mg} / \mathrm{kg}$ of the isomers.

\section{Ether}

While the duration of the anesthesia by inhalation of ether was slightly prolonged by treatment with $30 \mathrm{mg} / \mathrm{kg}$ of $l$ - and $d l$-isomers 30 minutes before, it was markedly prolonged by the same treatment with $d$-isomer. The time-length of the induction phase of anesthesia was also significantly shortencd by the treatment, but the effect was most marked in $d$-isomer and least in $l$-isomer. Consequently, the motor excitement during the phase of anesthesia was also depressed.

\section{Modification of $L D_{\mathrm{s},}$ of methamplietamine}

The simultaneous administration of 20 to $30 \mathrm{mg} / \mathrm{kg}$ of the isomers resulted in the increase of $\mathrm{LD}_{50}$ of methamphctamine in mice. 'The depressing effcct of xylopinine on the methamphetamine toxicity was most apparent in $l$-isomer. The $\mathrm{LD}_{50}$ of methamphetamine was $68(60$ to 76$) \mathrm{mg} / \mathrm{kg}$, while those in the mice treated with 20 and 30 $\mathrm{mg} / \mathrm{kg}$ of $\mathrm{l}$-isomer were $119(80$ to 179$)$ and 128 (91 to 179$) \mathrm{mg} / \mathrm{kg}$, respectively (at $\mathrm{P}=$ 0.05). The $\mathbf{L D}_{50}$ of methamphetamine in the mice treated similarly with 20 and 30 $\mathrm{mg} / \mathrm{kg}$ of $d l$ - and $d$-isomers was $116,120: 80$ and $100 \mathrm{mg} / \mathrm{kg}$, respectively. The increase of $\mathrm{LD}_{50}$ was smallest in $d$-isomer. The enhancement of the movement, the piloerection, salivary secretion, clcvation of the tail and impulsive movement by usc of methamphetamine were also depressed by the isomers. Even though large doses of $l$-isomer elicited 

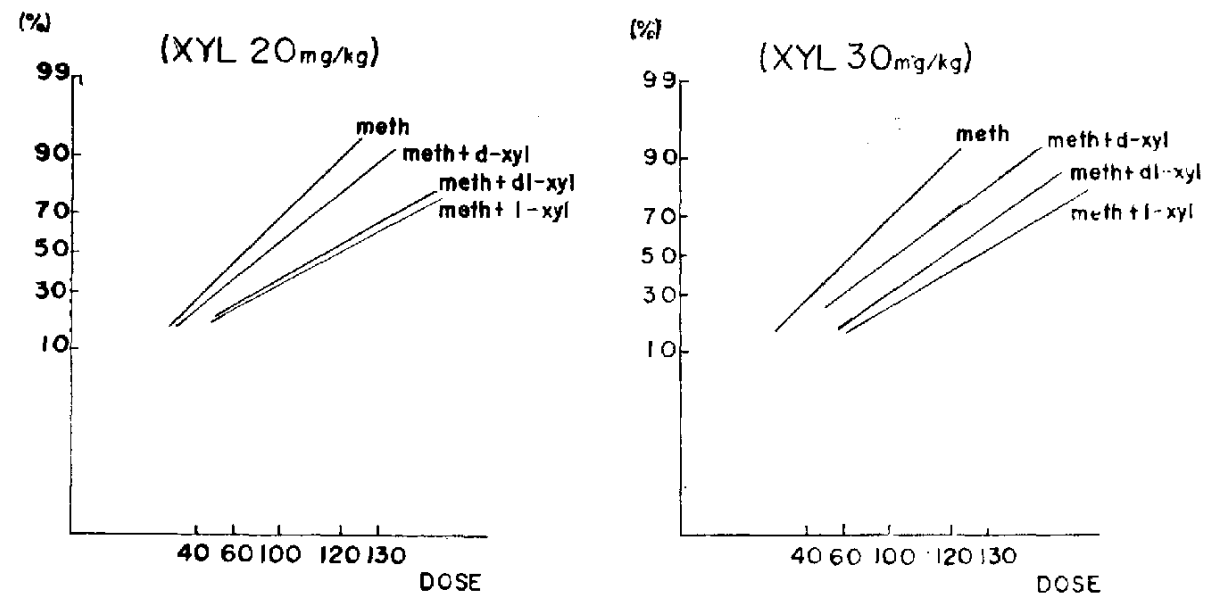

FIG. 3. Effects of the intraperitoneal injection of the isomers on the lethality of mice by the same procedure of methamphetamine.

the similar behavioral changes, the depressing effect of the isomers on bchavioral excitement caused by methamphetamine was most potent in $l$-isomer and weak in $d$-isomer (Fig. 3).

\section{Effects on blood pressure}

The intravenous administration of $l$-isomer produced a fall of blood pressure and a depression of respiration in dogs and rabbits. The falls of the mean blood pressure caused by 1,3 and $5 \mathrm{mg} / \mathrm{kg}$ were about 10,20 and $25 \mathrm{mmHg}$, which lasted for about 5,10 and 15 minutes in dogs. The similar but less lasting hypotension was observed in rabbits. The depressor response to $3 \mathrm{mg} / \mathrm{kg}$ of dl-isomer was much short lasting and fol-

Rabbit

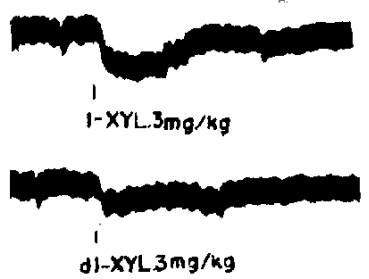

d)-XYL3mg/kg

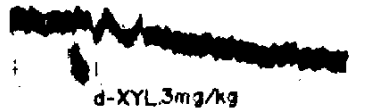

Lᄂ11LLLL11111111
Dor

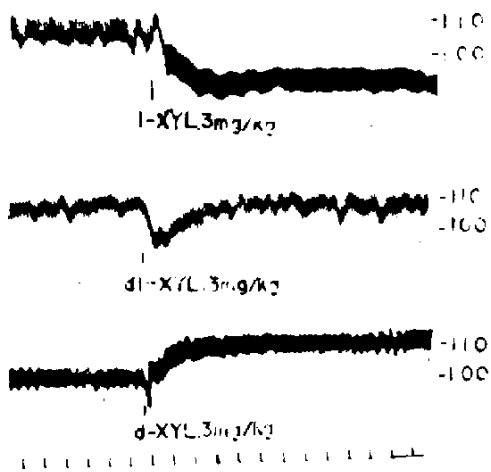

triit,

FIG. 4. Effects of the intravenous injection of $3 \mathrm{mg} / \mathrm{kg}$ of the isomers on the blood pressure in dog and rabbit. 
lowed with a slight but retarded rise in dogs. On the other hand, the administration of $d l$-isomer in rabbits produced a slight but long lasting fall. The administration of 1 to $5 \mathrm{mg} / \mathrm{kg}$ of $d$-isomer in dogs produced a slowly progressing and long lasting rise of blood pressure, while in the rabbit the same procedure resulted in a slowly developing fall of blood pressure (Fig. 4).

The pressor responses to the intravenous administration of $2 \mu \mathrm{g} / \mathrm{kg}$ of adrenaline and noradrenaline were markedly depressed by the previous treatment of dogs with 1 to $5 \mathrm{mg} / \mathrm{kg}$ of the isomers. The reduction of the pressor responses by use of $3 \mathrm{mg} / \mathrm{kg}$ of $l$-, $d l$ - and $d$-isomers was by 55,30 and $25 \%$, respectively. Thus, $l$-isomer showed most marked adrenolytic activity. Moreover, a certain large dose of $l$-isomer produced an adrenaline reversal.

The pressor response to the intravenous injection of $40 \mu \mathrm{g} / \mathrm{kg}$ of DMPP in dogs was also depressed by either amine. The depression of the response caused by $3 \mathrm{mg} / \mathrm{kg}$ of $l$-, $d l$ - and $d$-isomers was by 40,20 and $15 \%$, respectively. In this respect $l$-isomer proved to be most effective. Though the depressor response to the intravenous injection of 0.5 and $1.0 \mu \mathrm{g} / \mathrm{kg}$ of acetylcholine was not affected by the previous treatment in the dog with $3 \mathrm{mg} / \mathrm{kg}$ of cither amine, only the same treatment with $5 \mathrm{mg} / \mathrm{kg}$ of $l$-isomer depressed the response slightly.

\section{$V$. Effects on the contractile responses of the isolated vas deferens of guinea-pig}

\section{Effects on the responses to adrenaline and noradrenaline}

No response of the preparation was elicited by administration of $10^{-7}$ to $10^{-4}$ of either isomer. The concentrations of adrenaline or noradrenaline above $10^{-7}$ elicited a transient contraction followed with an increased outcome of the spontaneous rhythmicity. The previous trcatment of the preparation with the concentrations of $l$-isomer above $5 \times 10^{-8}$ for 3 minutes depressed the response to $10^{-7}$ of adrenaline. The $\mathrm{ED}_{50}$ of $l$-isomer for depressing the response was $2 \times 10^{-7}$, while those of $d l$-isomer and tolazoline hydrochloride were $4 \times 10^{-7}$ and $1.8 \times 10^{-6}$, respectively. On the other hand, $d$-isomer
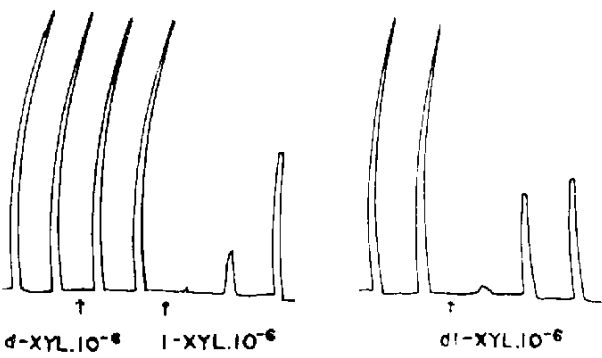

FIG. 5. Effects of $10^{-6}$ of the isomers on the responses of the isolatcd vas deferens of guinea-pig to $10^{-7}$ of adrenaline. 


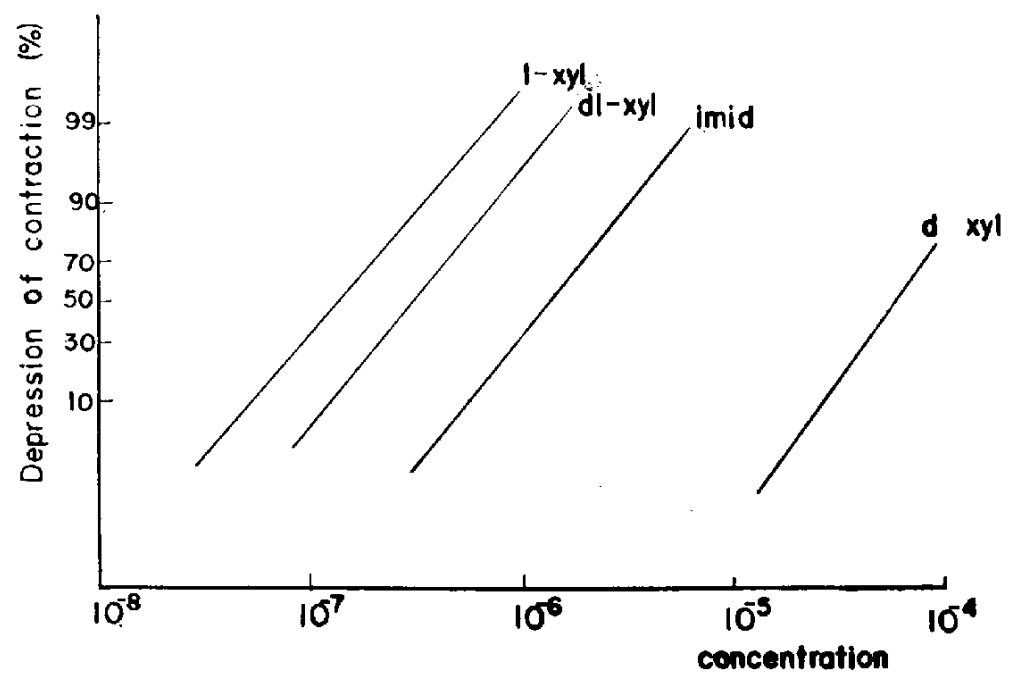

FIG. 6. Effects of the isomers and tolazoline on the contractile response of vas deferens to $10^{-7}$ of adrenaline.

proved a negligible effect and the $\mathrm{ED}_{50}$ was $7 \times 10^{-5}$. The similar depressing effects were observed on the response of the preparation to noradrenaline (Figs. 5 and 6).

\section{Effects on the response to acetylcholine}

The transient contraction of the preparation in response to $5 \times 10^{-8}$ of acetylcholine was depressed by $20 \%$ and $10 \%$ by the previous treatment with $10^{-4}$ of $l$-and $d l$-isomers, respectively. However, the same contraction of the preparation caused by the concentration of acetylcholine was not affected by the previous treatment with $d$-isomer in the concentrations below $10^{-4}$.

\section{Effects on the responses of the preparation to hypogastric stimulation}

The concentrations of either isomer above $5 \times 10^{-7}$ depressed the contraction of the vas deferens caused by stimulation of the hypogastric nerve, preceded with a transient increase in height. The early potentiating effect was most marked in $d$-isomer and weak in $l$-isomer. Similarly, the depressing effect was most marked in $d$-isomer and weak in $l$-isomer. Both effects of xylopinine were easily reversed by washing. The depressing: effect of either isomer in the low concentration such as $5 \times 10^{-t}$ was transient and recovered spontaneously without washing (Figs. 7 and 8). The potentiating effect of either isomer on the hypogastric response was almost completely abolished by atropinization of the preparation with $10^{-7}$.

\section{Effects on the potentiation of the hypogastric response by adrenaline and acetylcholine}

The concentrations of adrenaline above $5 \times 10^{-9}$ or of acetylcholine above $10^{-9}$ potentiated the contraction of the vas deferens elicited by stimulation of the hypogastric nerve. The potentiation caused by the former was depressed by the previous treatment 


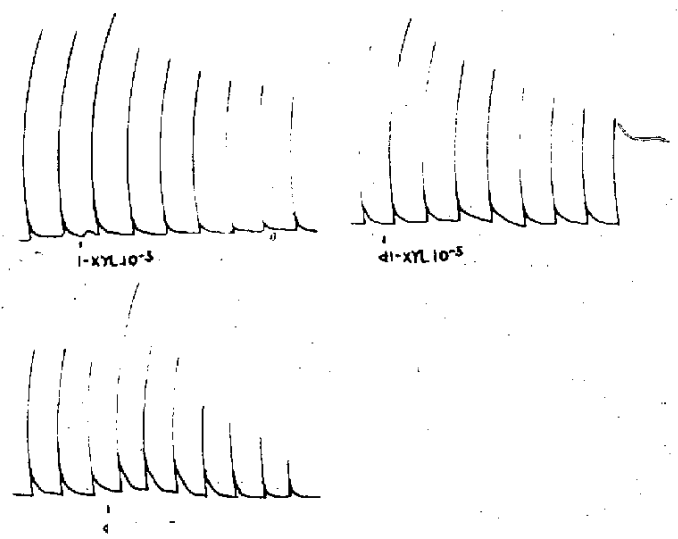

FIG. 7. The biphasic eflects of $10^{-5}$ of the isomera on the responses of the isolated vas deferens of guinea-pig to stimulation of the hypogastric nerve.

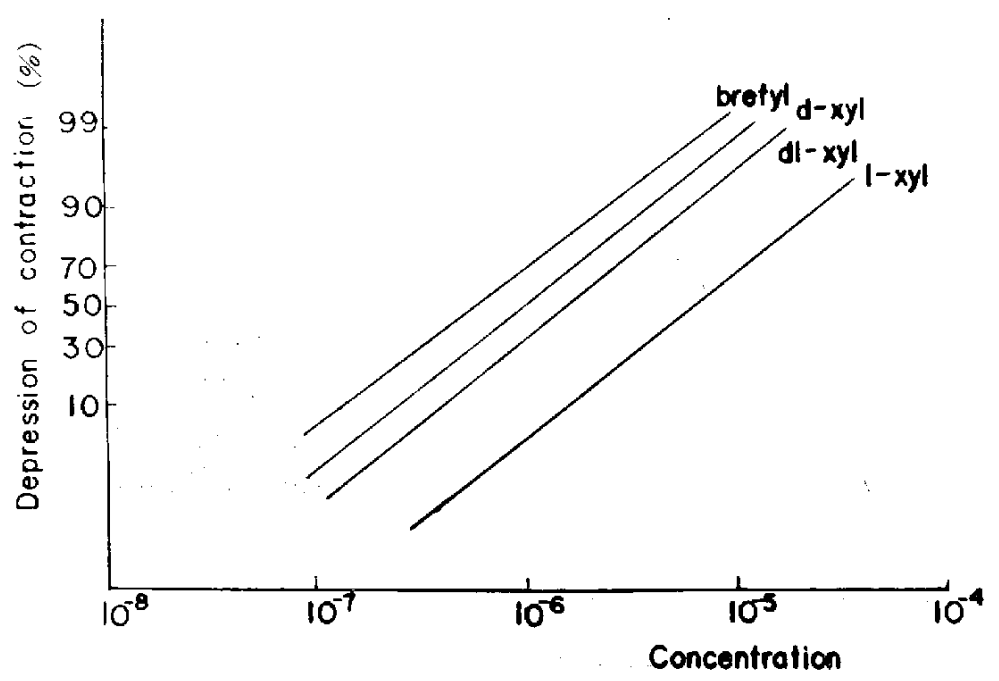

FIG. 8. Effects of the isomers and bretylium on the contractile responsc of vas deferens to hypogastric nerve stimulation in guinea-pig.

with either isomer in the concentration above $10^{-4}$ as well as by the treatment with tolazoline in the concentrations above $10^{-1 i}$. The potentiation caused by acetylcholine was similarly depressed by the previous treatment with either isomer in the concentrations above $10^{-6}$. Paradoxically, the potentiating concentrations of adrenaline depressed the contraction of the prcparation, treated previously with either isomer in the concentrations above $10^{-4}$, in response to the hypogastric stimulation. However, the same treatment did not modify the potentiating effect of acctylcholine. These effects of the isomers were easily reversed by washing.

VI. Effects on the inhibitory responses of the isolated ral's uterus to adrenaline and noradrenaline The concentrations of either isomer above $5 \times 10^{-5}$ depressed slightly the rhythmic 
contraction of the preparation. However, the depressive effects of adrenaline and noradrenaline on the uterine rhythmicity were not affected by either isomer.

VII. Effects on EEG in rabbits

1. Effects on the spontaneous EEGs recorded from the motor cortex and lipposampus

Immediately after the intravenous injection of $1 \mathrm{mg} / \mathrm{kg}$ of $l$-isomer the cortical EEG showed an increase in the slow waves, 1 to $3 \mathrm{cps}$, intermingled with the spindle waves, 8 to $15 \mathrm{cps}$. The previous regular arousal waves in the hippocampal EEG changed to the irregular resting waves. 'The resting waves in the EEGs elicited by 1 to $3 \mathrm{mg} / \mathrm{kg}$

A)

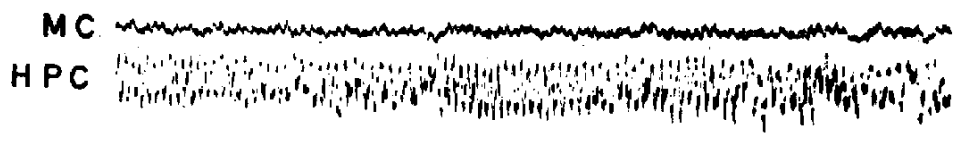

B)

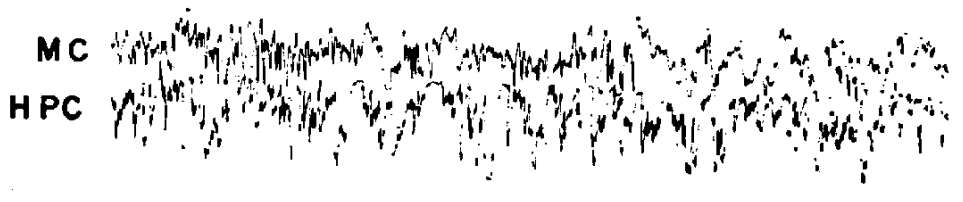

C)
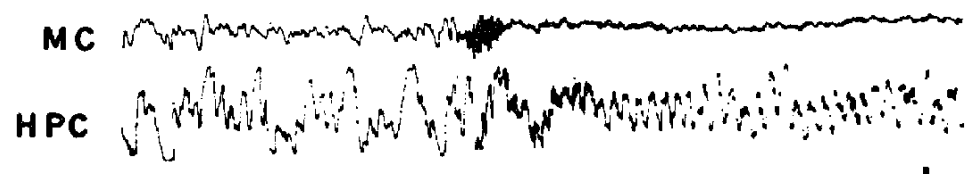

\section{$\prod_{\text {Isec }}^{\text {Joc }}{ }_{\mu \mathrm{V}}$}

FIG. 9-A. Effects of $l$-xylopinine on the spontaneous EEG in rabbit.

A) control, B) 30 minutes after and C) 90 minutes after.

MC : motor cortex, HPC : hippocampus.

A)

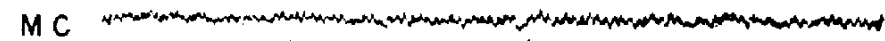

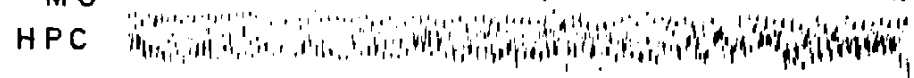

B)

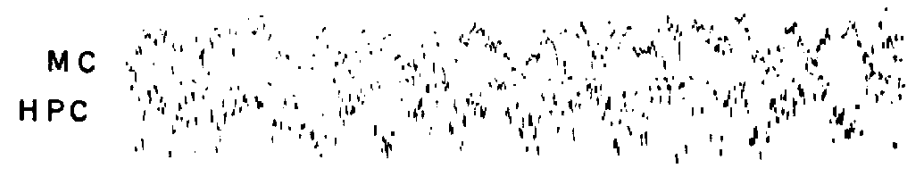

C) MC

$\prod_{100}^{1000 m}$

FiG. 9-B. Effects of $d l$-xylopinine on the spontancous EEG in rabbit.

A) control, B) 30 minutes after and C) 90 minutes after.

$\mathrm{MC}$ : motor cortex, HPG : hippocampus. 
A)

MC

B) MC

C)

\section{MC}

HPC

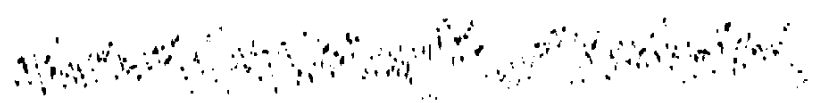

\section{$\prod_{\text {lece }}^{\text {loow }}$}

FIG. 9-G. Effects of $d$-xylopinine on the spontancous EEG in rabbit.

A) control, B) 30 minutes after and C) 90 minutes after.

MC : motor cortex, HPC : hippocampus.

of $l$-isomer lasted for 1 to 1.5 hours, while further incrcasc in dosage shortened the duration of the resting waves (Fig. 9-A).

One $\mathrm{mg} / \mathrm{kg}$ of $d l$-isomer resulted also in manifestation of the resting waves in the cortical and hippocampal EEGs, the duration of the manifestation was shorter than that caused by $l$-isomer ( $/$ ig. $9-\mathrm{B}$ ). On the other hand, the administration of $d$-isomer in the doses smaller than $4 \mathrm{mg} / \mathrm{kg}$ did not affect the spontaneous EEGs, and the same procedure in the doses above $5 \mathrm{mg} / \mathrm{kg}$ produced the arousal waves in both EEGs, which lasted for 1 to 2 hours. Only in one of 10 rabbits received the large doses of $d$-isomer, the arousal waves lasting for several hours were followed with the resting waves (Fig. $9-\mathrm{C})$.

\section{Effects on the reticular and thalamic arousal responses}

Stimulation of the brain stem reticular formation with repetitive square wavcs, $200 / \mathrm{sec}$ in frequency, 1 msec in cluration and 0.3 to 1.5 volts in intensity, resulted in manifestation of the arousal waves in the cortical EEG. During manifestation of the resting waves caused by $\mathrm{l} \mathrm{mg} / \mathrm{kg}$ of $l$-isomer, the threshold voltage to elicit the arousal response was elevated, and the peak elevation by about $60 \%$ of the previous level was attaincd at 45 minutcs after the administration. Though the reticular stimulation evoked also the arousal waves in the hippocampal EEG, the elevation of stimulation threshold was not so marked as that in the cortical EEG. One $\mathrm{mg} / \mathrm{kg}$ of $d$-isomer clicited the similar but considerably slight clcvation of the threshold. The peak elevation at 45 minutes after the administration was by $35 \%$. During the manifestation of the slight arousal waves caused by $d$-isomer in the doses above $5 \mathrm{mg} / \mathrm{kg}$, the reticular stimulation threshold was slightly lowered and the peak lowering at 30 minutes after the administration was by $10 \%$. However, from 1.5 to 2 hours after the administration the lowering of the threshold turned gradually to an elevation (Fig. 10). 


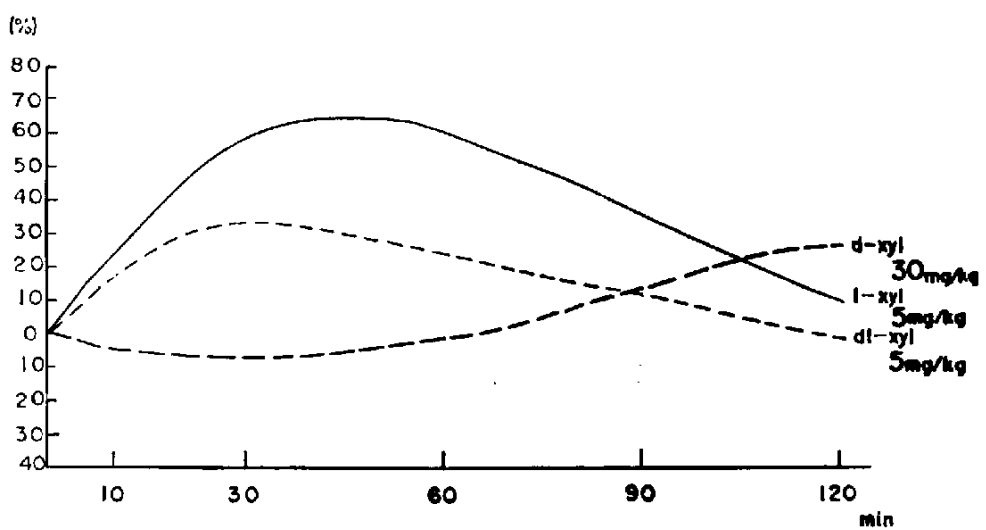

FIG. 10. The time course of the changes of the reticular threshold for the arousal response caused by the icomers in rabbit.

During manifestation of the resting waves in both cortical and hippocampal EEGs caused by $l$ - and $d l$-isomers in the doses above $1 \mathrm{mg} / \mathrm{kg}$, the stimulation threshold for the thalamic arousal response was significantly elevated almost similarly in time course with the threshold elevation for the reticular arousal response. On the other hand, the administration of $d$-isomer in the doses above $20 \mathrm{mg} / \mathrm{kg}$ lowercd slightly the thalamic threshold lasting for 1.5 to 2 hours followed with some elevation.

\section{Effects on the recruiting response}

Stimulation of the Nucleus centre médian of the thalamus with repetitive square waves, $8 / \mathrm{sec}$ in frequency, $1 \mathrm{msec}$ in duration and 0.7 to 1.7 volts in intensity, resulted in manifestation of the recruiting response in the cortical EEG. From immediately after the intravenous administration of 1 to $5 \mathrm{mg} / \mathrm{kg}$ of $l$-isomer, the recruiting threshold was gradually elevated and no recovcry was attained at least within several hours after the administration. The same dose of $d l$-isomer produced significantly less clevation of the

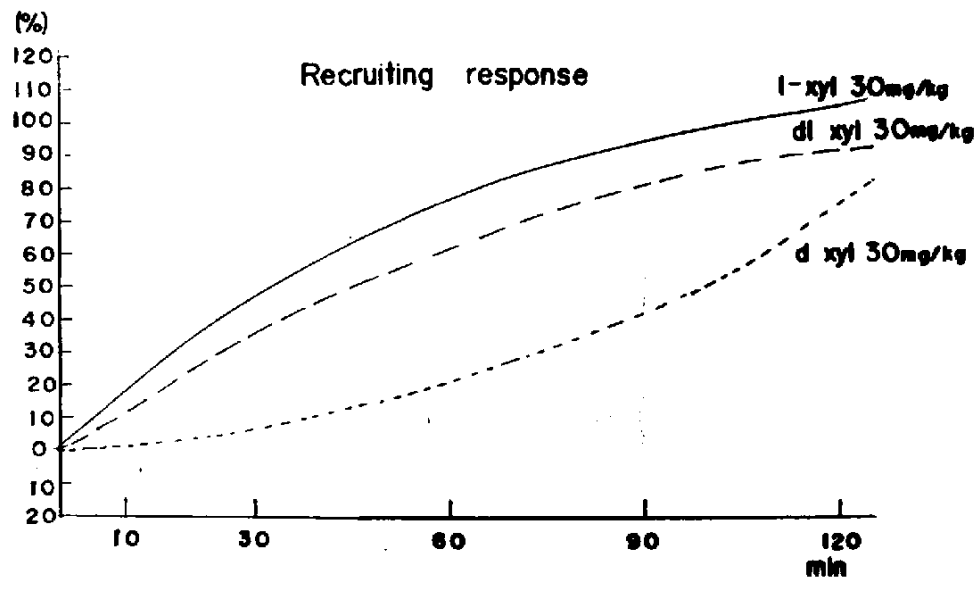

FIG. 11. Effects of the isomers on the thalamic threshold for the recruiting response in the rabbit. 
threshold. On the other hand, even 5 to $10 \mathrm{mg} / \mathrm{kg}$ of $d$-isomer did not affect the threshold until about 1.5 hours after the administration. Thereafter, the recruiting threshold elevated gradually and no recovery was observed within scveral hours (Fig- 11).

\section{DISCUSSION}

Pasteur's idea that two optical isomers, although they have same chemical reactivity, may form compounds with different physical and therefore, biological properties by reaction with asymmetric ccll rcceptors, have remained the basis of explanation for difference in biological activity found between vast numbers of stercoisomers. Some qualitative differences have also been reported to exsist between the stereoisomers of 1(3,4-dihydroxyphenyl)-2-aminopropanol and 1-(3,4-dihydroxyphenyl)-2-aminopropane (6). The comparative pharmacological study of the optical isomers of xylopinine in the present experiments showed quantitative as well as qualitative difference in effects on a varicty of the structures.

The behavioral study of xylopinine in mice demonstrated the resemblance of the isomers in depressing the spontaneous movement and respiration, $d$-isomer differed from $l$ - and $d l$-isomers, which activated the avoidance reflcxes and produced sympathomimetic effects, in depression of the reflexes and in lack of the latter effect. Morcover, in contrast to the rapid lethality of mice by either $l$ - or $d l$-isomer by repeating clonic-tetanic convulsion, $d$-isomer elicited a retarded dcath without manifesting convulsion. The $\mathrm{LD}_{50}$ of $l$-isomer was signiffcantly smaller than that of $d l$-isomer.

The quantitative differences between the isomers were found in prolonging effect on hexobarbital anesthesia and also in prevention of the methamphetamine lethality in mice. The former effect of $l$-isomer manifested earlier than that of $d$-isomer, but it was short-lasting. The prolongation of hexobarbital anesthesia by $d$-isomer was long-lasting and the peak effect was attained 30 to 60 minutes after the administration. In addition, l-isomer depressed motor excitement of mice during the induction phase of the anesthesia, while $d$-isomer was less effective in this respect. Further, $l$-isomer prevented more effectively the amphetamine lethality than $d$-isomer. These effects of $d$-isomer, resembling rather to those of $l$-isomer, were always intermediary.

Some species difference in the responses of blood pressure to the isomers was found between dogs and rabbits. Though $l$-isomer produced the hypotension in both species, the duration of the response was longer in dogs than in rabbits. Further, $d$-isomer produced a long-lasting pressor response in dogs, but a gradually progressive hypotension in rabbits. The adrenolytic activity in dogs was stronger in $l$-isomer than in $d$ isomer. The similar dominance of $l$-isomer to $d$-isomer was observed on the depressing effect against the pressor response to DMPP in dogs. Further, only l-isomer depressed the depressor response to acetylcholine in dogs.

Nakanishi (1) has reported that $l$-isomer cxhibits adrenolytic effect in blood pressure of dogs, cats and rabbits, and adrenolytic and sympathicolytic effects in the nictitating membrane of cats. The comparison of the adrenolytic effect of these isomers in the 
isolated vas deferens of guinea-pig demonstrated that $l$-isomer was most active and then $d l$-isomer, and $d$-isomer was almost negligible. Even $d l$-isomer was more active than tolazoline in this respect. The contractile response of the preparation to acetylcholine was also inhibited by high concentrations of $l$-and $d l$-isomers but not by that of $d$ isomer. Inhibition of the hypogastric response of the preparation by tolazoline and phenoxybenzamine has been demonstrated by Boyd $e t$ al. (7). They have reported that the sympathicolytic effect of the adrenergic blocking agents does not run parallel with the adrenolytic effect.

These isomers produced a biphasic effect on the hypogastric response of the preparation, early but transient potentiation followed with late and long-lasting depression. The potentiating effect was marked in $d$-isomer than in $l$-isomer. The similar potentiating effects of phenoxybenzamine and tolazoline were postulated by Boyd et al. (7) to derive from inhibition of tissue cholinesterase. The depressing effect of $d$-isomer on the hypogastric response of the vas deferens was much stronger than that of $l$-isomer, which exhibited stronger adrenolytic activity. Therefore, it seemed that the sympathicolytic mechanism of xylopinine differed somewhat from the adrenolytic onc. The sympathicolytic effect of xylopininc, which was easily reversed by washing of the prcparation, differed also from the similar but irreversible effect of bretylium (8).

The contractile responsc of vas dcferens to acetylcholine was depressed by $l$ - and $d l$-isomers in high concentrations but not by $d$-isomer. Burn and Rand (9) postulated that the cholincrgic mechanism was involved in release of the endogenous noradrenaline. The evidence, cited above, allows the assumption that $l$-and $d l$-isomers interfer with the release of noradrenaline by the added acetylcholine, while $d$-isomer is inert in this respect. The depressing effect of adrenaline and not of acetylcholine on the contractilc response of vas deferens treated previously with high concentration of xylopinine should be regarded to derive from the inhibitory mechanism of catecholamine. The conclusion was supported by the evidence that the inhibitory response of the isolated rat's uterus to adrenaline was not affected by xylopinine.

The manifestation of the resting waves in the cortical and hippocampal EEGs by $l$-isomer in rabbits demonstrated by Nakanishi $(1,2)$ was also confirmed in the present experiments. In this respect $d l$-isomer proved to be less effectivc. However, $d$-isomer, which did not affect the EEGs in small doses, produced a manifestation of the arousal waves in large doses. In accord with manifestation of the resting waves, the reticular and thalamic stimulation thresholds for the arousal response were markedly elevated by $l$-isomer and slightly by $d l$-isomer. On the other hand, $d$-isomer lowered the same thresholds for 1 to 2 hours followed with a considerable elevation, thereafter. The recruiting response in the cortical EEG was markedly elevated by $l$-isomer and slightly by $d l$-isomer and no recovery was attained within several hours after the administration. Moreover, 1 to 2 hours after the administration of large doses of $d l$-isomcr the recruiting threshold turned to gradually developing and sustained elcvation. 


\section{SUMMARY}

The optical isomers of xylopinine hydrochloride were pharmacologically compared in mice, rats, guinea-pigs, rabbits and dogs.

1. The isomers depresscd the spontaneous movement and respiration in mice. The $l$ - and $d$-isomers activated the avoidance reflexes with a concomitant appearance of the sympathomimetic excitement, while $d$-isomer depressed the reflexes lacking of the excitement. The former isomers killed the animals by producing a clonic or clonic-tetanic convulsion.

2. The isomers prolonged the duration of anesthesia caused by hexobarbital and urethane in mice. The prolonging effect by the simultaneous administration with the anesthetics was most marked in $l$-isomer and least in $d$-isomer, while the same effect in mice treated with isomers 30 to 60 minutes before was most marked in $d$-isomer and least in $l$-isomer.

3. The $l$-isomer proved to be most effective in preventing the methamphetamine death in mice and $d$-isomer to be least.

4. The depressor effect of $l$-isomer in dogs was long-lasting, while it was transient in rabbits. On the other hand, $d$-isomer in dogs produced a long-lasting rise of blood pressure, while it in rabbits a gradually developing but sustained fall.

5. The isomers depressed the responses of the isolated guinea-pig's vas deferens to adrenaline and $l$-isomer was most active in this respect. However, the isomers produced a biphasic cffect on the response to hypogastric stimulation. The late depressing effect was most marked in $d$-isomer and least in $l$-isomer. The isomers depressed also the potentiating cffect of adrenaline and acetylcholine on the hypogastric response of the preparation and adrenaline inhibited the contractile response of the preparation, treated previously with high concentrations of the isomers, to hypogastric stimulation.

6. $l$-Isomer and $d l$-isomer evoked a manifestation of the resting waves in the cortical and hippocampal EEGs as well as the reticular and thalamic stimulation threshold for the arousal response. $d$-Isomer, which was inactive on the EEG in small doses, produced the manifestation of the arousal waves associated with some lowering of the arousal stimulation threshold. The effects were followed with retarded and long-lasting elcvation of the arousal and recruiting thresholds.

\section{REFERENCES}

1) Nakanisili, H. : Tilis Journal 12, 208 (1962)

2) NAKANislit, H. : lbid. 14, 317 (1964)

3) YAMAMOTO, H. : Ibid. 13, 230 (1963)

4) Higuchi, H., Matsuo, T., Nakatani, G. and Shimamoto, K. : Ibid. 13, 36 (1963)

5) Huković, S. : Brit. J. Pharmacol. 16, 188 (1961)

6) Schalmann, O. : Scientia Pharm. 21, 342 (1953)

7) Boyd, H., Chang, V. and Rand, M.J. : Brit. J. Pharmacol. 15, 525 (1960)

8) BExTLLY, G.A. : 1bid. 19, 85 (1962)

9) Burn, J.H. And Rand, M.J. : J. Physiol. 150, 296 (1960) 